\title{
Avaliação da eficiência de sistemas de proteção de superfície para concreto: absorção de água, migração de cloretos e ângulo de contato
}

\author{
Efficiency of surface protection systems \\ for concrete: water absorption, chloride \\ migration and contact angle
}

\author{
Marcelo Henrique Farias de Medeiros ${ }^{1}$, Eduardo Pereira ${ }^{2}$, \\ Andrielli Scardanzan Figura ${ }^{2}$, Felipe Maués Tissot ${ }^{2}$, Karen Alves Artioli ${ }^{2}$
}

\footnotetext{
${ }^{1}$ Av. Governador Agamenon Magalhães, 239 - Ap. 102A - Torre I - Cristo Rei, Curitiba, PR CEP: 80050-510 e-mail:medeiros.ufpr@gmail.com

2 e-mail:engenheiroeduardopereira@gmail.com, andriellisfigura@yahoo.com.br, felipetissot@ hotmail.com, ,karen.artioli@gmail.com
}

\section{RESUMO}

A camada de cobrimento do concreto funciona como uma barreira natural ao ingresso de agentes agressivos para o interior do material, dificultando a penetração de íons cloretos, reduzindo a absorção de água e limitando o acesso de oxigênio. Para garantir a eficiência desta camada protetora o uso de tratamentos de superfície mostra-se como uma alternativa viável para prolongar o período de proteção proporcionado pelo cobrimento do concreto. O objetivo deste trabalho é estudar o efeito de proteção de quatro produtos disponíveis no mercado para ser aplicados na proteção de superfície de concretos (cimento quartzoso, epóxi, silicatos, silano/siloxano), bem como comparar os métodos usados para investigar a eficiência de sistemas de proteção. Para isto procedeu-se sobre corpos de prova de concreto, ensaios de absorção por sucção capilar, resistência à penetração de cloretos por migração de íons e medição do ângulo de contato com a água sobre a superfície de concreto protegida ou não. Os produtos estudados apresentaram a capacidade de modificar a interação entre a água e a superfície de contato do concreto. Dentre os produtos estudados, o epóxi é o que apresenta a maior resistência à penetração de cloretos, menor absorção de água por capilaridade e caráter hidrófugo. Com exceção dos silicatos, verificou-se ainda uma boa correlação entre os resultados de absorção de água por capilaridade e o ensaio de migração de íons cloretos. Os produtos Epóxi e a base de silicatos, que apresentaram os menores valores de sortividade, foram os que apresentaram os maiores valores de ângulo de contato, sendo classificados como os de menor afinidade com a água.

Palavras-chave: Proteção de superfície, Durabilidade, Concreto armado, Cloretos.

\section{ABSTRACT}

The thickness of concrete cover acts as a natural protective barrier to the ingress of aggressive agents into the material, hindering the penetration of chloride ions, reducing water absorption and by limiting access of oxygen. To ensure the efficiency of this protective coat the use of surface treatments presents as a viable alternative to extend the period of protection provided by the concrete cover. The aim of this study is to evaluate the protective effect of four products available on the market to be applied on the surface protection of concrete (concrete sealers, epoxy, silicates and silane/siloxane) and compare the methods used to investigate the efficiency of protection systems. Absorption test by capillary suction, chloride penetration resistance by migration of ions and measuring the contact angle with water on the surface of protected concrete were executed. The studied products presented the ability to modify the interaction between the water and the contact surface of the concrete. With the exception of silicate, it was verified a good correlation between the results of water absorption by capillary and chloride ions migration. Among the studied products, the epoxy presents the highest resistance to chloride penetration, lower water absorption by capillarity and water repellent character. 
The epoxy and silicate, which showed the lowest values sorptivity, presented the highest values of contact angle, being ranked as the lowest affinity for water.

Keywords: Surface protection, Durability, Reinforced concrete, Chlorides.

\section{INTRODUÇÃO}

Em condições normais, a armadura de aço no concreto armado encontra-se protegida fisicamente por uma barreira que consiste no cobrimento do concreto. Esta barreira dificulta o ingresso de substâncias que podem dar início ao processo de corrosão, bem como limita o acesso de água e oxigênio para o interior do material. Tendo o concreto boa qualidade, alta densidade e alta resistividade elétrica, ele estará menos susceptível à movimentação iônica, o que dificulta o início do processo de corrosão.

Entretanto, o sistema contínuo de poros do concreto e sua tendência a formar fissuras superficiais, podem prejudicar a eficiência da camada de cobrimento como barreira. Desse modo, para garantir o efeito barreira proporcionado pelo cobrimento de concreto, muitas vezes são utilizados revestimentos aplicados sobre as armaduras ou sobre a superfície do concreto. Neste contexto, os tratamentos de superfície são alternativas para elevar o tempo de vida útil das estruturas de concreto armado, uma vez que cria-se uma camada de proteção frente ao ingresso de agentes agressivos no concreto.

O objetivo deste trabalho é estudar o potencial de proteção de quatro produtos disponíveis no mercado para ser aplicados na proteção de superfície de concretos. Também é foco do trabalho comparar os métodos usados para investigar a eficiência de sistemas de proteção, que é um campo sem normas nacionais para seu controle de qualidade.

Alguns outros trabalhos nesta linha foram desenvolvidos e publicados por estes autores previamente $[1,2]$, porém, a novidade da presente pesquisa é o emprego da determinação do ângulo de contato com a água e a inclusão do epóxi como alternativa de sistema de proteção de superfície.

\subsection{Proteção de superfície sobre concreto armado}

De acordo com Ho e Mark [3], o processo de corrosão no concreto armado com proteção de superfície aplicada deve ser mais lento devido ao menor conteúdo de umidade interna. Esta afirmação é correta porque a cinética das reações de corrosão de armaduras é altamente dependente da quantidade do eletrólito. Contudo, outro efeito importante dos sistemas de proteção de superfície é a restrição ao ingresso de agentes agressivos para o interior do material.

Apesar disso, Broomfield [4] afirma que se o processo de corrosão das armaduras do concreto contaminado por cloretos já estiver iniciado é improvável que qualquer tipo de proteção de superfície iniba o processo, uma vez que a presença no interior do concreto de umidade e oxigênio são suficientes para continuidade do processo de corrosão.

Deve-se destacar que a opinião de Broomfield [4] e Ho e Mark [3] são conflitantes e Medeiros [5] executou um experimento que corrobora com a opinião de Ho e Mark [3] . Desse modo, de acordo com Medeiros e Helene [6], Diamanti et al. [7] e Brenna et al. [8], em uma estrutura em que o processo de corrosão já está instalado, a proteção de superfície apresenta efeito de redução da velocidade de corrosão devido ao seu poder de reduzir a absorção de água do concreto armado. Com a restrição do ingresso de água, a cinética do processo de corrosão pode ser reduzida drasticamente em função da magnitude da capacidade do sistema de proteção de superfície em reduzir a absorção de água do sistema.

Sabe-se ainda que a eficiência de uma proteção de superfície é diminuída ao longo do tempo de exposição ao meio ambiente. Desse modo, a garantia da funcionalidade dos produtos de proteção de superfície aplicados em concreto está no estabelecimento de um programa de manutenção, considerando que cada material tem uma vida útil limitada. Isso tudo leva a concluir que a aplicação de uma pintura de proteção sobre uma estrutura de concreto sem planejamento da sua manutenção deve ser julgada como desperdício de material e de recursos financeiros. Além disso, deve-se levar em conta que o tempo de vida útil de um material de proteção de superfície depende muito das condições de exposição a que ele é submetido em serviço. Sabe-se que zonas de variação de maré consistem na condição de exposição mais severa, no que se refere ao ataque por cloretos, como também definido por Zemajtis e Weyers [9].

Os serviços de conservação do concreto podem estar incluídos em um programa de manutenção preventiva ou em um programa de manutenção corretiva. $O$ primeiro caso vai intervir no concreto antes que ele apresente sinais significantes de degradação. Infelizmente, na construção civil nacional, o caso mais comum é o de manutenção corretiva, onde os trabalhos de manutenção são típicos de correção de manifestações pato- 
lógicas, ou seja, existe necessidade de um diagnóstico prévio do problema para a identificação das causas, e então proceder à proteção do concreto. Isto traz como consequência um maior custo de trabalho de manutenção e provável redução da vida útil da estrutura em questão [10]. De qualquer forma, é reconhecido que os sistemas de proteção têm uma vida útil relativamente curta quando comparados com as estruturas de concreto armado, devendo ser periodicamente inspecionados para identificar a necessidade de manutenção, com vistas a manter sua funcionalidade.

Os materiais de proteção de superfície para concreto podem ser classificados em formadores de película, hidrofugantes de superfície (de poro aberto) e bloqueadores de poros, como representado na Figura 1. O conjunto de materiais usados neste trabalho compreende representantes das 3 categorias da Figura 1.

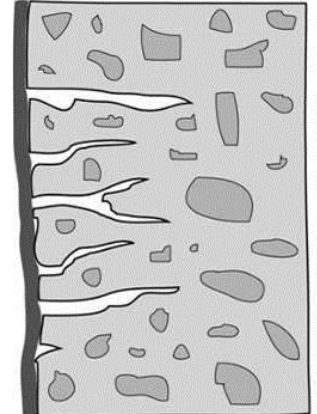

(a)

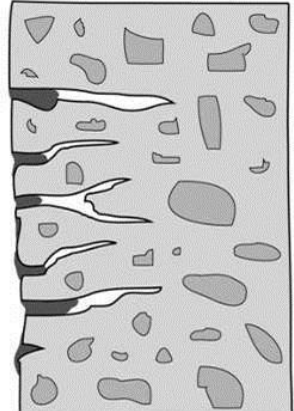

(b)

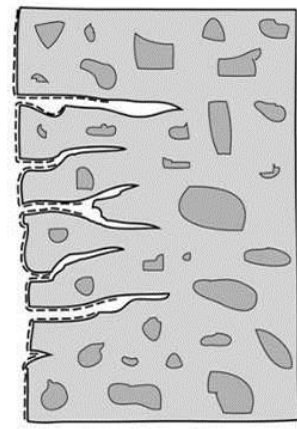

(c)

Figura 1: Grupos de tratamentos de superfície para concreto: (a) formadores de película (b) bloqueadores de poros (c) hidrofugantes de superfície (adaptado de [11]).

Poucas informações são atualmente disponibilizadas sobre o tempo de vida útil dos sistemas de tratamento de superfície disponíveis no mercado para aplicação em estruturas de concreto armado. A necessidade de desenvolver procedimentos e formalizar parâmetros através de normas nacionais é uma necessidade no contexto brasileiro. Um exemplo de informação, ainda que genérica e voltada para a realidade de outro país é sobre o tempo de ação de produtos hidrofugantes de superfície. Christodoulou et al. [12], realizando trabalhos de inspeção em viadutos localizados no Reino Unido, construídos na década de 70 e posteriormente tratados com hidrofugante de superfície, demonstraram que o tratamento do concreto armado com silano apresenta eficiência residual comprovada em termos de redução de absorção de água mesmo 20 anos após a aplicação do tratamento. Essa informação gera a reflexão sobre a necessidade de desenvolvimento de ensaios acelerados para embasar a tomada de decisão na especificação de sistemas de proteção nas diversas aplicações de engenharia, mas também de estudar estruturas reais submetidas às intempéries de modo realístico e tentar aprender com estes casos reais e se possível retroalimentar a forma de avaliar os produtos por ensaios acelerados.

\section{MATERIAIS E MÉTODOS}

A estratégia da pesquisa consistiu em fixar um proporcionamento de concreto para o substrato de teste dos sistemas de proteção de superfície, sendo usado com base para aplicação dos quatro sistemas de proteção usados nesta pesquisa. Isso gerou cinco séries de comparação: série de referência, Produto A (Cimento quartzoso), Produto B (Epóxi), Produto C (Silicatos) e Produto D (Silano/siloxano).

Na pesquisa foram realizados três ensaios: 1 - absorção por sucção capilar (de acordo com a NBR 9779 [13]), 2 - Ensaio de resistência à penetração de cloretos por migração de íons (de acordo com a ASTM C 1202 [14]) e 3 - Ensaio de medição do ângulo de contato com a água sobre a superfície protegida (de acordo com a ASTM D 7334 [15]).

Para cada ensaio foram moldados quatro corpos de prova, de modo que o total de corpos de prova foi de 5 séries de comparação x 3 ensaios x 4 corpos de prova somados a 4 corpos de prova para avaliação da resistência à compressão aos 28 dias do concreto do substrato, totalizando 64 corpos de prova cilíndricos de $10 \times 20 \mathrm{~cm}$.

Para o concreto empregado como substrato utilizou-se o traço de 1:1,81:2,70 (cimento:areia:brita), com relação água/cimento de 0,55 . Como citado, quatro corpos de prova foram submetidos ao ensaio de re- 
sistência à compressão axial de acordo com a NBR 5739 [16] apresentando como resultado 37 MPa. Seguindo a NBR 12655:2006, a resistência característica foi calculada de acordo com a Equação 1, usando Sd igual a $4 \mathrm{MPa}$. O valor de resistência característica foi de $30 \mathrm{MPa}$, caracterizando este concreto como um concreto convencional.

$$
\mathrm{f}_{\mathrm{cd}}=\mathrm{f}_{\mathrm{ck}}+1,65 . \mathrm{S}_{\mathrm{d}}
$$

Onde: $\mathrm{fcd}=$ resistência de dosagem $(\mathrm{MPa})$; fck = resistência característica $(\mathrm{MPa}) ; \mathrm{Sd}=$ desvio padrão (MPa).

Nesta pesquisa foram avaliados quatro produtos - de diferentes fabricantes - quanto à eficiência na proteção contra a penetração de água e de íons cloreto no concreto. Uma descrição resumida dos 4 produtos comparados está indicada na Tabela 2.

Tabela 2: Produtos de proteção de superfície estudados.

\begin{tabular}{|c|c|c|}
\hline Classificação & Mistura & Descrição do fabricante \\
\hline $\begin{array}{l}\text { Bloqueador de poros } \\
\text { (Cimento quartzoso) }\end{array}$ & $\begin{array}{c}\text { Monocomponente } \\
\text { (em pó) }\end{array}$ & $\begin{array}{l}\text { Base química: mistura de cimento, quartzo e componentes quí- } \\
\text { micos ativos em forma de pó; } \\
\text { Aspecto: Pó cinza; } \\
\text { Produto reage com a umidade e com a cal livre presente no con- } \\
\text { creto formando cristais - insolúveis - que vedam as microfissu- } \\
\text { ras e os poros do concreto, impedindo assim a passagem de água; } \\
\text { A dosagem do produto é feita seguindo a proporção de 1:2,5 } \\
\text { (água:pó), misturando-se até formar uma pasta homogênea. }\end{array}$ \\
\hline $\begin{array}{l}\text { Formador de película } \\
\text { (Epóxi) }\end{array}$ & $\begin{array}{l}\text { Verniz epóxi - bi- } \\
\text { componente com } \\
\text { baixa viscosidade }\end{array}$ & $\begin{array}{l}\text { Base Química: Epóxi; } \\
\text { Aspecto: Líquido Incolor; } \\
\text { Massa Específica: } 1,7 \mathrm{~g} / \mathrm{cm}^{3}\end{array}$ \\
\hline $\begin{array}{l}\text { Bloqueador de poros } \\
\text { (Silicatos) }\end{array}$ & Monocomponente & $\begin{array}{l}\text { Base Química: Silicatos de Sódio e Potássio; } \\
\text { Aspecto: Líquido Incolor; } \\
\text { pH: } 12,0+\text { ou } 1,0 ; \\
\text { Massa Específica: } 1,23 \mathrm{~g} / \mathrm{cm}^{3} \\
\text { Teor de Sólidos: } 28,0 \% \pm 1,4 \text {. }\end{array}$ \\
\hline $\begin{array}{l}\text { Hidrofugante de superfície } \\
\text { (Silano/siloxano) }\end{array}$ & Monocomponente & $\begin{array}{l}\text { Base Química: Silano/siloxano disperso em água; } \\
\text { Aspecto: Líquido Banco; } \\
\text { Massa Específica: } 0,99 \mathrm{~g} / \mathrm{cm}^{3} \text {. }\end{array}$ \\
\hline
\end{tabular}

\subsection{Ensaios realizados}

\section{Ensaio de Absorção de Água por sucção capilar (NBR 9779: 1995):}

Este ensaio tem como objetivo determinar a absorção de água por capilaridade em concretos e argamassas endurecidos. Para isto, seguiu-se os procedimentos estabelecidos na NBR 9779 [13].

O recipiente usado para este ensaio possui dimensões adequadas para o posicionamento dos corpos de prova, além de um dispositivo hidráulico que garante o nível de água constante. Os corpos de prova foram colocados sobre suportes e o recipiente preenchido com água, de modo que o nível de água permanecesse constante em $5 \pm 1 \mathrm{~mm}$ acima da face apoiada dos corpos de prova (Figura 2-a). Para evitar a absorção de água pela superfície lateral de cada CP, foi aplicada uma camada de silicone antes do ensaio (Figura 2-b).

A resposta do ensaio foi medida a partir da pesagem dos corpos de prova, após secagem da superfície em contato com a água, ao longo do tempo de exposição à lâmina de água do recipiente. Estas pesagens foram realizadas nos tempos de 10min, 20min, 30min, 45min, $1 \mathrm{~h}, 1 \mathrm{~h} 15,1 \mathrm{~h} 30,1 \mathrm{~h} 45,2 \mathrm{~h}, 2 \mathrm{~h} 30,3 \mathrm{~h}, 4 \mathrm{~h} 30,6 \mathrm{~h}$, $24 \mathrm{~h}, 48 \mathrm{~h}$ e $72 \mathrm{~h}$.

A absorção de água foi calculada de acordo com a Equação 2.

$$
Q=\frac{A_{t}-B}{S}
$$


Onde: $\mathrm{Q}=$ absorção de água por capilaridade $\left(\mathrm{g} / \mathrm{cm}^{2}\right) ; \mathrm{A}_{\mathrm{t}}=$ massa do corpo de prova pesado no tempo $\mathrm{t}(\mathrm{g})$; $\mathrm{B}=$ massa do corpo de prova seco $(\mathrm{g}) ; \mathrm{S}=$ área da seção transversal $\left(\mathrm{cm}^{2}\right)$.

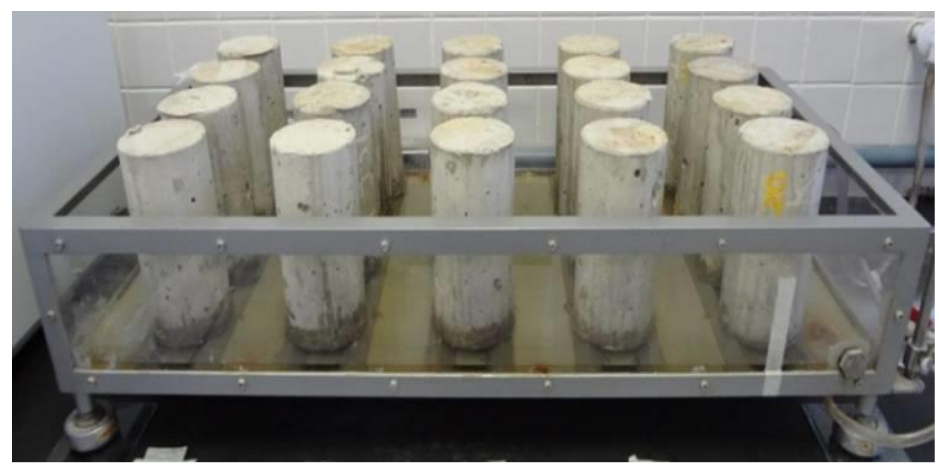

(a)

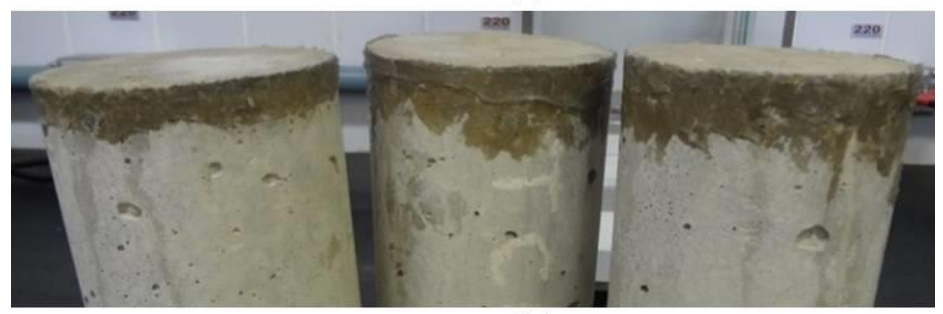

(b)

Figura 2: Ensaio de absorção de água por capilaridade: (a) Aparato de absorção por sucção capilar; (b) Detalhe do silicone na lateral dos corpos de prova.

\section{Resistência à penetração de cloretos por migração de íons (ASTM C 1202: 2012):}

Como a penetração real de cloretos em uma peça de concreto armada é bastante lenta, bem como o ensaio de difusão de cloretos, neste estudo foi realizado o ensaio de migração de cloretos para estimar a capacidade do concreto (protegido ou não) de resistir à penetração de íons cloreto.

Baseado no estudo de Medeiros, Hoppe Filho e Helene [17], que comprova que a retirada de três fatias de um mesmo corpo de prova cilíndrico (Ø $10 \times 20 \mathrm{~cm}$ ) não compromete a precisão dos resultados, foram extraídas duas fatias centrais de cada corpo de prova, ao contrário da prática de muitos pesquisadores que utilizam apenas uma fatia central.

Cada fatia foi tratada com o sistema de proteção a ser testado, resultando em oito fatias para cada sistema de proteção de superfície e oito para a amostra de referência, sem proteção de superfície.

Seguindo as recomendações da ASTM C 1202 [14], as fatias tiveram a sua lateral curva revestida com silicone e passaram por um processo de saturação, utilizando vácuo e imersão, de acordo com os seguintes procedimentos: todas as fatias foram colocadas num dessecador que foi conectado a uma bomba de vácuo ligada por $3 \mathrm{~h}$; o recipiente foi preenchido com água destilada, cobrindo totalmente todas as fatias; a bomba de vácuo foi ligada por $1 \mathrm{~h}$; a bomba de vácuo foi desligada e o recipiente permaneceu em repouso por $18 \mathrm{~h} \pm$ 2 h. A Figura 3 mostra a proteção lateral com silicone e o processo de saturação em execução. 


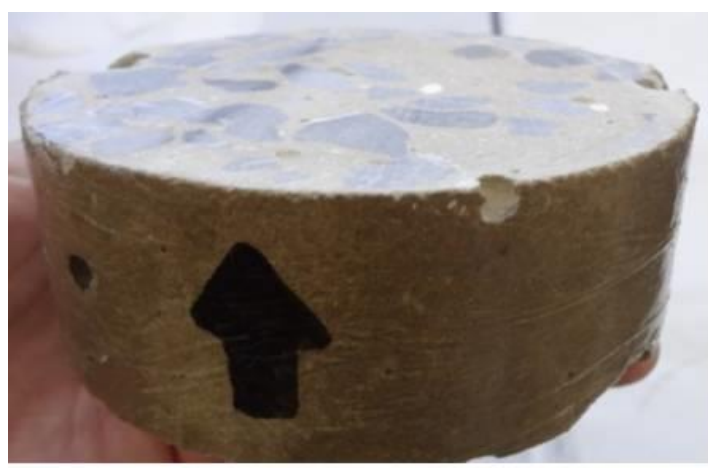

(a)

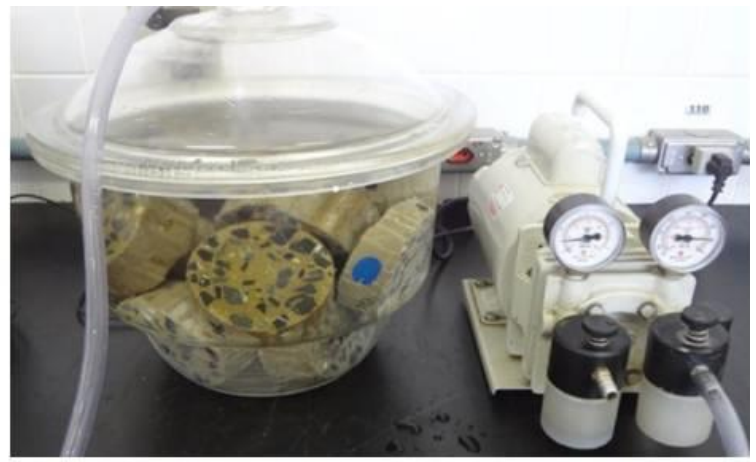

(b)

Figura 3: Etapas de preparo das fatias para o ensaio de migração de íons cloretos: (a) Fatia com lateral protegida com silicone; (b) Dessecador e bomba de vácuo para a saturação das fatias.

Em seguida, cada fatia foi colocada num par de células de acrílico, com eletrodos de cobre, e seladas com silicone (Figura 4-a) sendo posteriormente ligadas em série como ilustrado na Figura 4-b.

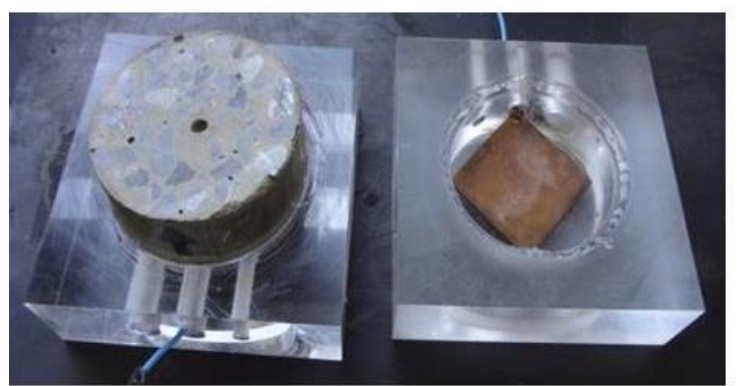

(a)

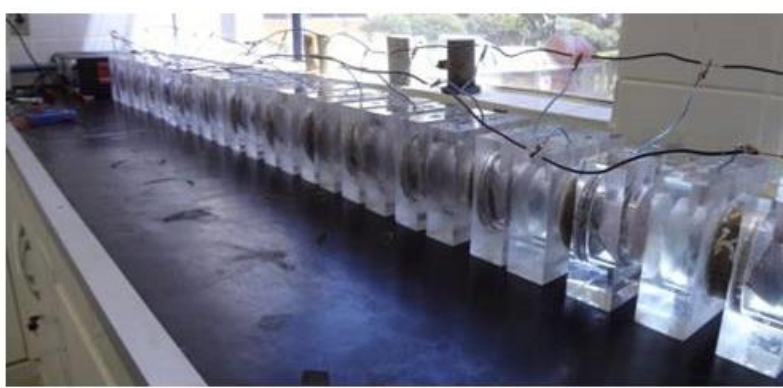

(b)

Figura 4: Detalhe da montagem do ensaio de migração de íons cloretos: (a) Célula de migração sendo montada; (b) Células de migração montadas em série.

Antes da ligação em série, as células foram preenchidas com soluções aquosas de $3 \%$ de $\mathrm{NaCl}$ - respectiva ao lado da fatia com o sistema de proteção de superfície - e $0,3 \mathrm{~N}$ de $\mathrm{NaOH}$ - correspondente ao lado da fatia sem tratamento. A ligação elétrica de cada célula foi feita de maneira que o polo negativo (-) foi ligado à célula com solução aquosa de $\mathrm{NaCl}$ e o polo positivo (+) foi ligado à célula com solução aquosa de $\mathrm{Na}-$ $\mathrm{OH}$. Este procedimento baseou-se no princípio de atração dos polos, ou seja, o polo positivo (+) irá atrair os íons cloreto $\left(\mathrm{Cl}^{-}\right)$, carregados negativamente. Todas as células foram ligadas em série a um gerador de energia (como já indicado na Figura 4-b), sendo mantidos constantes $60 \mathrm{~V}$ de diferença de potencial ao longo das 6 horas de ensaio. O resultado final do ensaio é o valor de carga passante, em A/s ou Coulomb (C), que é obtida calculando a integral da curva da corrente passante (medida a cada 30 minutos) ao longo das 6 horas de ensaio. A Figura 5 apresenta um esquema detalhado da célula de migração empregada neste ensaio. 


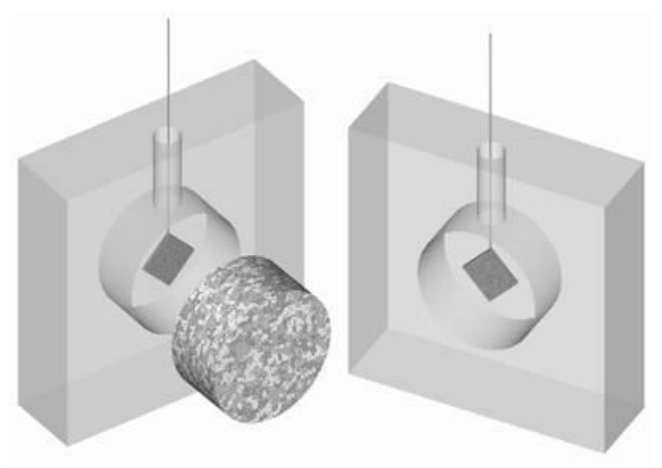

Perspectiva explodida da célula

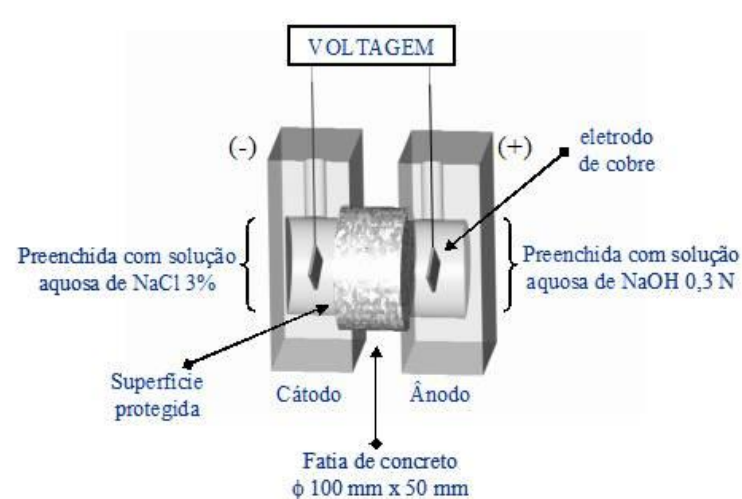

Figura 5: Esquema da célula de migração empregada (MEDEIROS, 2008).

\section{Ângulo de contato com a água sobre a superfície protegida (ASTM D 7334: 2008)}

As forças capilares que permitem a penetração de líquidos através dos poros do concreto são influenciadas pela viscosidade do líquido, pelo raio dos poros e pelo ângulo de contato entre o líquido e o material. Os dois primeiros são constantes no caso da água em um determinado concreto, sendo assim, apenas o ângulo de contato $(\alpha)$ pode ser alterado [10].

Segundo a ASTM D 7334 [15], o ângulo de contato é o ângulo entre um plano tangente a uma gota do líquido e um plano contendo a superfície onde o líquido se encontra depositado, conforme ilustrado na Figura 6. Esta norma também estabelece que uma superfície é hidrofílica se $\alpha<45^{\circ}$ e é hidrofóbica se $\alpha>90^{\circ}$ ou intermediário se $45^{\circ}<\alpha<90^{\circ}$. No primeiro caso ocorre a atração molecular entre o líquido e o substrato e, desse modo, as gotas tendem a se espalhar na superfície do concreto e são absorvidas (Figura 6-a). Já no segundo caso, a atração entre o líquido e o substrato é pequena e as gotas tentem a ficar esféricas (Figura 6-b).

O ensaio de medição do ângulo de contato da gota d'água com o concreto protegido foi adotado nesse programa experimental buscando uma correlação com os resultados obtidos no ensaio de absorção de água por capilaridade. O procedimento adotado no ensaio foi o que consta na ASTM D7334 [15] e é baseado na goniometria, que envolve a observação de uma gota d'água sobre a superfície protegida dos corpos de prova.

Uma gota de água deionizada de 20 microlitros foi aplicada a superfície utilizando uma pipeta de precisão marca Digipet (Figura 7-a) e o ângulo de contato foi medido através de um microscópio equipado com um goniômetro conforme ilustrado na Figura 7-b, denominado de goniômetro de baixo custo desenvolvido no laboratório de Engenharia de Materiais da Universidade Estadual de Ponta Grossa.
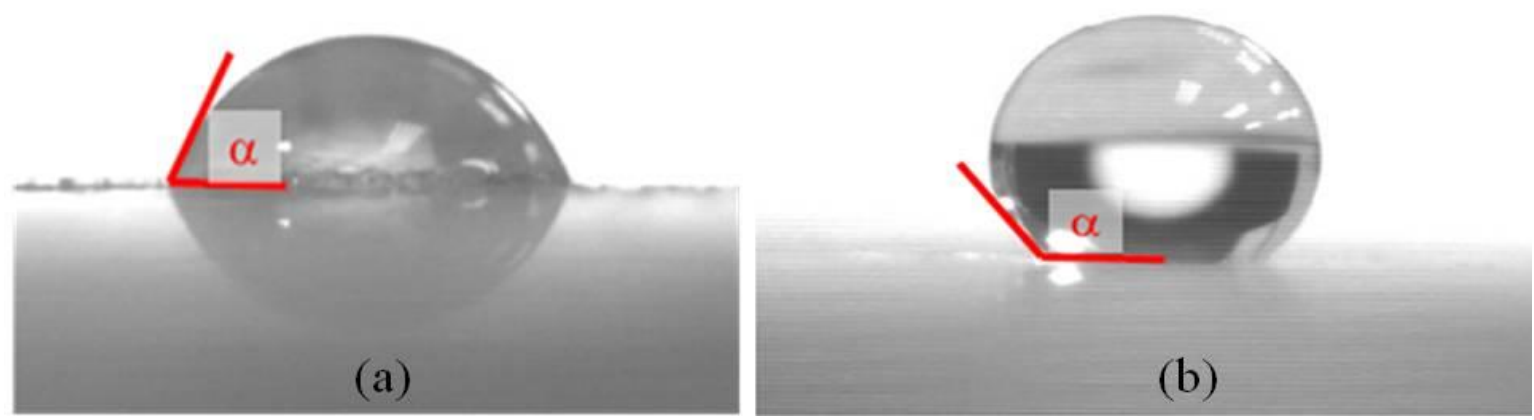

Figura 6: Ângulo de contato de uma gota d'água em uma superfície de contato: (a) superfície hidrofílica se $\alpha<45^{\circ}$; (b) superfície hidrofóbica se $\alpha>90^{\circ}$ [18]. 

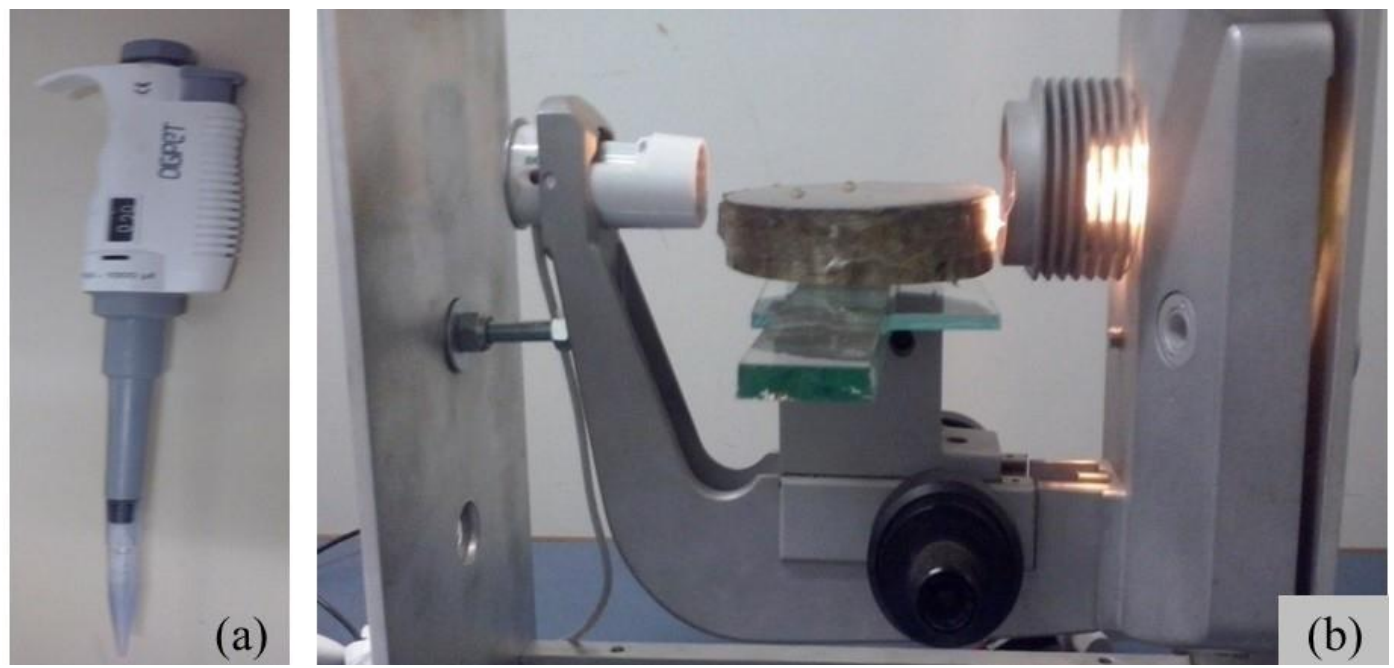

Figura 7: Pipeta de precisão e Goniômetro usado no estudo: (a) pipeta de precisão marca Digipet; (b) Goniômetro de baixo custo.

\section{RESULTADOS E DISCUSSÃO}

Este trabalho apresenta resultados de absorção de água por capilaridade, resistência à penetração de cloretos por ensaio de migração de íons e ângulo de contato entre a água e as superfícies tratadas. Os resultados são detalhados a seguir.

\subsection{Absorção de Água por Capilaridade}

A sucção capilar é um importante mecanismo de transporte com relação ao ingresso de cloretos no concreto. Sua atuação está presente nos casos em que o concreto não está saturado, de modo que se este entra em contato com a solução salina, ela é absorvida por forças capilares [19].

Este tipo de mecanismo de transporte pode ser considerado uma das maiores causas de contaminação do concreto por cloretos, agindo nos casos onde existem condições cíclicas de umedecimento e secagem. Dependendo da umidade do concreto, no período de umedecimento a superfície do concreto absorve a solução de cloretos instantaneamente. No período da secagem a água evapora enquanto o sal permanece na estrutura de poros do concreto. Este processo tende a ocorrer de forma cíclica, fazendo com que a concentração de cloreto no concreto possa até superar a concentração da solução de cloretos em contato com o concreto [్].

O valor da absorção de água foi obtido por meio da divisão da massa de água absorvida pela área da seção circular de cada corpo de prova. A Figura 8 mostra o resultado deste ensaio, representando o monitoramento da absorção ao longo do tempo de ensaio.

Pode-se notar que o desvio padrão é bem maior nas medidas dos corpos de prova tratados com o produto a base de cimento quartzoso. Uma possível explicação é a característica física do produto em si, de modo que, se tratando de um produto muito parecido com argamassa, admite-se que este irá absorver mais água do que os outros.

Ao analisar o comportamento do Epóxi, nota-se uma grande capacidade em limitar a penetração de água pelos poros do concreto, indicando absorção quase zero durante todo o tempo do ensaio. Esta característica pode ser um fator fundamental para promover elevada eficiência do sistema de proteção.

Os produtos à base de silicatos e de silano/siloxano tiveram um comportamento muito semelhante entre si e se mostraram eficientes em reduzir a penetração de água por absorção por sucção capilar.

Como esperado, os corpos de prova da série de referência apresentaram os valores mais altos de absorção, visto que estes não foram tratados superficialmente com nenhum produto e é uma característica marcante do concreto não tratado apresentar alta capacidade de sucção de água para dentro da sua rede de poros. 


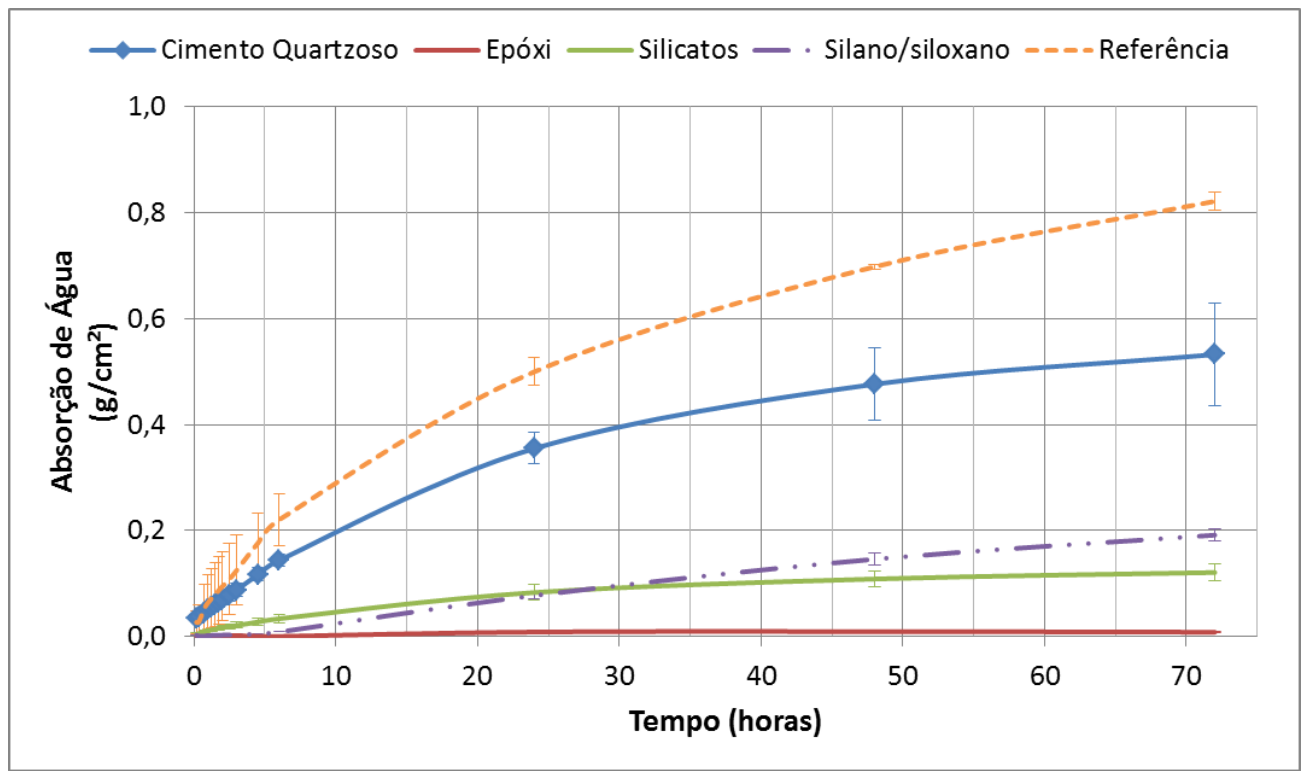

Figura 8: Absorção de água $X$ tempo para os corpos de prova com e sem tratamento de superfície.

Utilizando a curva de absorção de água ao longo do tempo para cada caso, foram calculados os valores de absortividade, $\mathrm{S}\left(\mathrm{mm} / \mathrm{h}^{1 / 2}\right)$, que é obtida experimentalmente pela declividade da curva de volume de água absorvida por unidade de área (da superfície em contato com a água) pela raiz quadrada do tempo, como representado na Equação 3.

$$
S=\frac{V_{\text {agua }}}{A \sqrt{t}}
$$

Onde: $\mathrm{V}_{\text {água }}=$ volume de água absorvida pelo corpo-de-prova $\left(\mathrm{mm}^{3}\right) ; \mathrm{A}=$ área da superfície em contato com a água $\left(\mathrm{mm}^{2}\right) ; \mathrm{t}=$ tempo de contato com a água $(\mathrm{h})$.

A absortividade representa a velocidade de penetração da água nos momentos iniciais e é dependente das características superficiais do concreto, que são fatores determinantes da sua durabilidade [20]. Os resultados de absortividade para cada caso, e seus respectivos desvios padrão, estão representados na Figura 9.

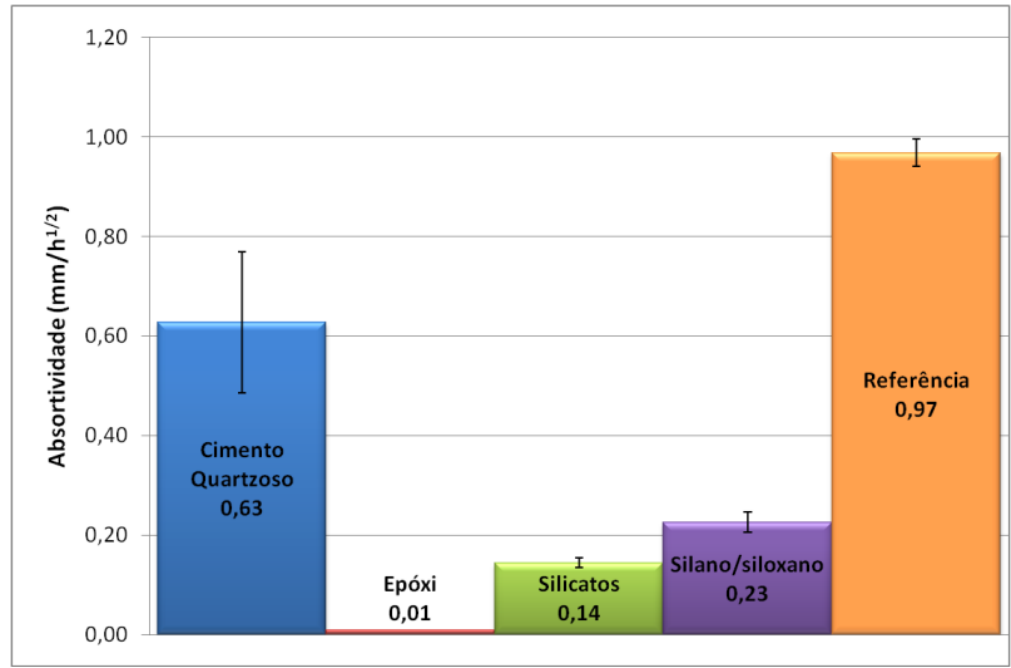

Figura 9: Resultado de absortividade das amostras ensaiadas.

Como esperado, os dados de absortividade apresentam o mesmo comportamento dos dados de absorção de água por sucção capilar, uma vez que ela constitui apenas outra forma de representar o resultado do 
mesmo ensaio. Desse modo, a série de referência obteve uma maior absortividade, seguido do cimento quartzoso, do produto a base de silicatos e do produto a base de silano/siloxano (com níveis de eficiência semelhantes) e o Epóxi como a menor absortividade entre todos os casos estudados neste trabalho.

O comportamento apresentado pelo epóxi pode ser explicado pelo mecanismo de atuação deste, através da formação de uma película polimérica sobre a superfície do concreto. Os demais materiais agem através do bloqueio de poros e pela ação hidrofugante de superfície. A película formada tende a ser mais homogênea sobre o concreto além de apresentar uma espessura maior do que a formada pelos demais produtos.

\subsection{Penetração de cloretos}

Os resultados dos ensaios de resistência à penetração de cloretos realizado de acordo com a ASTM C 1202 [14] estão apresentados na Figura 10. A Tabela 3 indica os limites de classificação deste tipo de ensaio.

Tabela 3: Potencial de penetração de íons cloreto de acordo com a carga passante (ASTM C 1202 [14]).

\begin{tabular}{l|l}
\hline Carga passante (Coulomb) & Penetrabilidade de Cloretos \\
\hline$>4000$ & Alta \\
\hline $2000-4000$ & Moderada \\
\hline $1000-2000$ & Baixa \\
\hline $100-1000$ & Muito Baixa \\
\hline$<100$ & Negligenciável \\
\hline
\end{tabular}

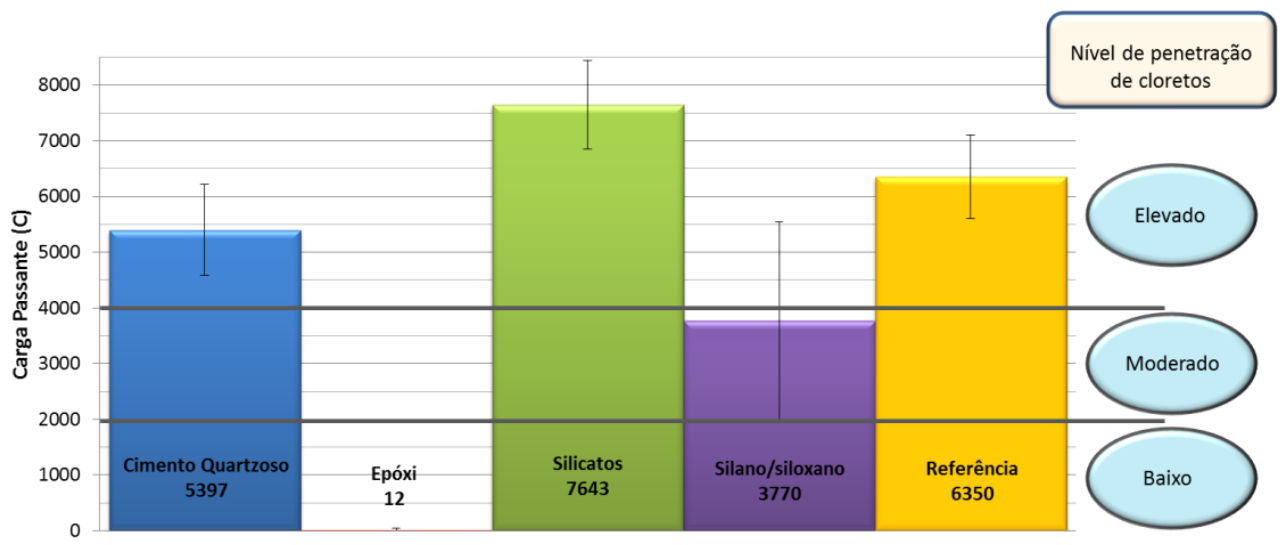

Figura 10: Carga passante de cada caso estudado em ensaio de acordo com a (ASTM C 1202 [14]).

No ensaio de migração de cloretos, o produto Epóxi apresentou o melhor comportamento indicando carga passante quase nula. $\mathrm{O}$ produto silano/siloxano também teve um comportamento razoável em ambos os ensaios. Este comportamento está dentro do esperado, visto que quanto menor a absorção de água, menor deve ser a migração de cloretos - já que é a água absorvida que transporta os cloretos para dentro dos poros do concreto. Apesar do comportamento médio do silano/siloxano de potencial de penetração de íons cloreto ser classificado como moderado, verificou-se elevado desvio padrão nos resultados desta amostra, indicando que estudos adicionais devem ser conduzidos buscando reduzir esta variabilidade.

Quanto ao produto a base de cimento quartzoso, que obteve um comportamento melhor do que a série de referência no ensaio de absorção de água, o resultado no ensaio de migração de cloretos indicou uma média de carga passante inferior, indicando certa capacidade de elevação de resistência ao ingresso de cloretos. Porém, deve-se destacar que os desvios padrão do produto a base de cimento quartzoso e da série de referência não permitem afirmar que a resistência à penetração de cloretos de ambos os casos sejam estatisticamente diferentes.

$\mathrm{O}$ resultado do tratamento à base de silicatos indica que nem sempre existe uma relação direta entre $\mathrm{o}$ resultado de absorção por capilaridade e a penetração de cloretos, como aconteceu com os demais casos testados neste experimento. No caso do tratamento de silicatos, o produto apresentou ótima capacidade de redução da absorção por capilaridade, porém resultou no pior resultado no ensaio de migração de cloretos. Apesar de os resultados estarem conflitantes com o observado em outros trabalhos como Medeiros e Helene [1] e 
Medeiros [5], no qual os autores verificaram valores de carga passante menores do que os concretos de referência, os resultados obtidos nesta pesquisa estão de acordo com o apresentado por Raisdorfer et al. [21] que utilizaram o mesmo produto comercial. Provavelmente a película superficial formada pela camada de silicato possa estar retendo o sódio e decompondo a molécula de água, deixando passar o íon hidroxila através do material, o que explicaria o aumento da carga passante.

A Figura 11 apresenta correlações entre os resultados de absorção por sucção capilar de água e o ensaio de migração de cloretos. Nota-se que existe certa relação entre os resultados, porém, a curva se ajustou com um $\mathrm{R}^{2}$ de 0,611 , indicando um índice de correlação relativamente fraco. Mas é fácil visualizar pela Figura 11 que o tratamento à base de silicatos é um ponto fora da curva, indicando que este produto se comporta de forma diferente dos demais.

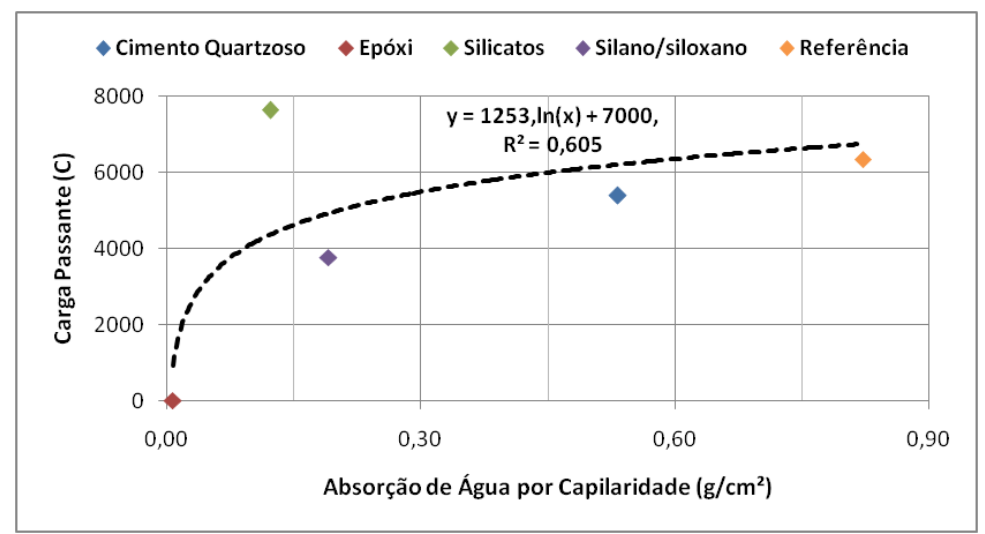

Figura 11: Correlação entre os ensaios de absorção de água por capilaridade e migração de cloretos.

Baseado nos dados analisados eliminou-se o ponto relativo ao tratamento de silicatos e a curva de correlação foi novamente plotada, conforme a Figura 12. O resultado apresenta uma melhora do ajuste da curva aos pontos, com $\mathrm{R}^{2}$ igual a 0,997 , indicando uma forte correlação entre os dados.

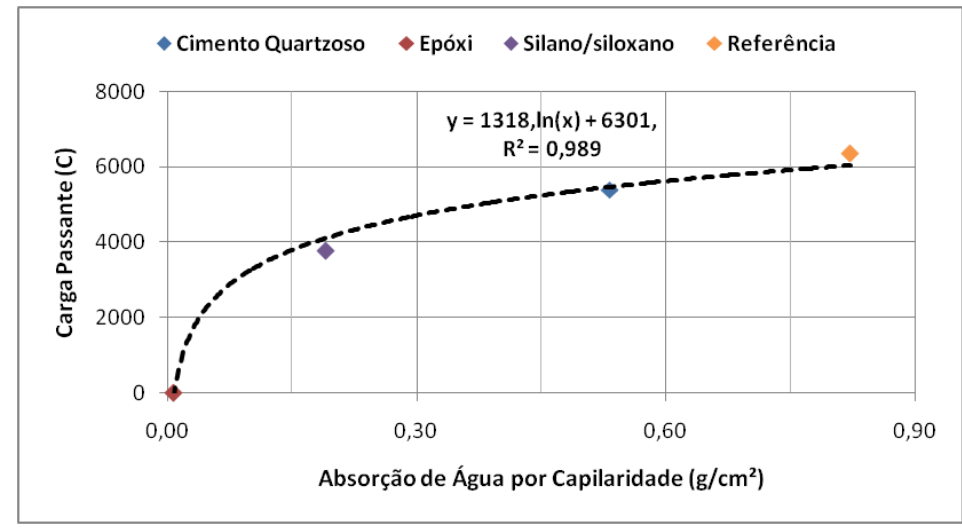

Figura 12: Correlação entre os ensaios, desconsiderando o tratamento de silicatos.

A melhora na correlação dos resultados entre carga passante e absorção por capilaridade ao retirar-se os resultados para o tratamento à base de silicatos demonstra que este tratamento necessita de estudos adicionais a fim de melhor compreender os fenômenos físicos ou químicos que expliquem o comportamento atípico para o produto.

\section{3 Ângulo de contato com a água}

Como apresentado anteriormente, o ângulo de contato é uma grandeza que tem relação com o grau de afinidade que um material tem com a água. A Figura 13 ilustra que o ângulo de contato da água é diferente para cada uma das séries testadas neste trabalho. Ou seja, as imagens deixam evidente que a aplicação de produtos de proteção de superfície sobre o concreto é capaz de mudar a afinidade com a água da superfície tratada. 


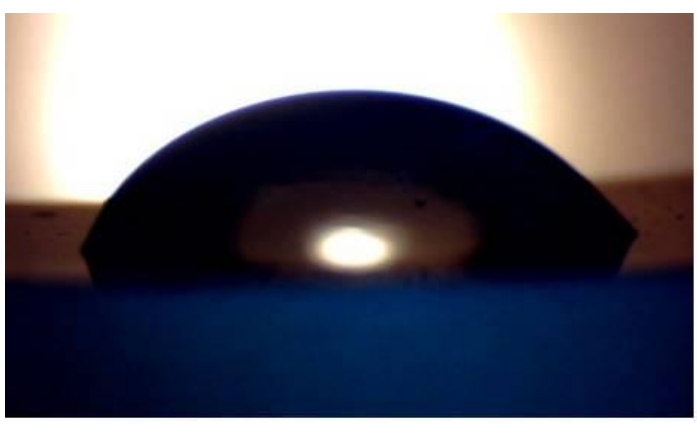

Referência

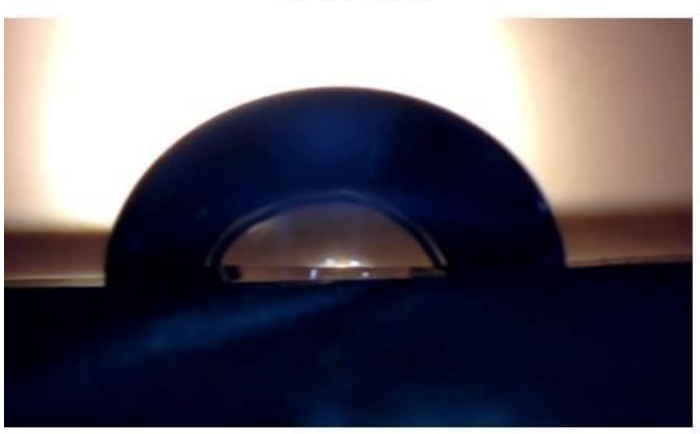

Epóxi

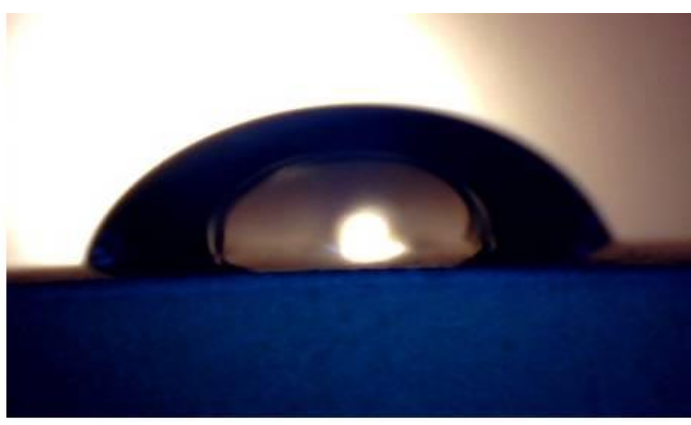

Silano/siloxano

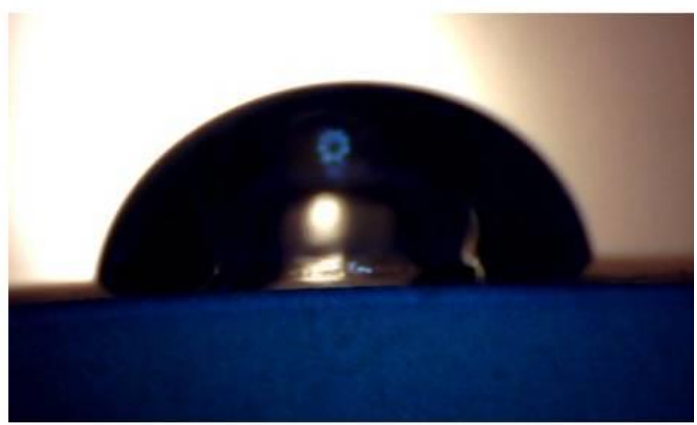

Silicatos de sódio e de potássio

Observação: Não houve possibilidade de leitura no caso do produto Grace M5, o que significa que o ângulo de contato é zero. Material com elevada afinidade com a água.

Figura 13: Configuração morfológica de uma gota de água em contato com as superfícies testadas.

A Figura 14 apresenta o ângulo de contato entre as superfícies testadas (série de referência e as séries com os produtos de proteção) e uma gota de água aplicada sobre ela. Deve-se notar que o produto a base de cimento quartzoso apresentou ângulo de contato igual a zero, ou seja, alta afinidade com a água, que é um indicativo de baixa eficiência de proteção superficial. Estes resultados estão de acordo também com o verificado nos resultados de absorção, absortividade e penetração de cloretos, onde este apresentou, após o concreto de referência, os maiores valores para estes ensaios, indicando a ineficiência do tratamento de superfície.

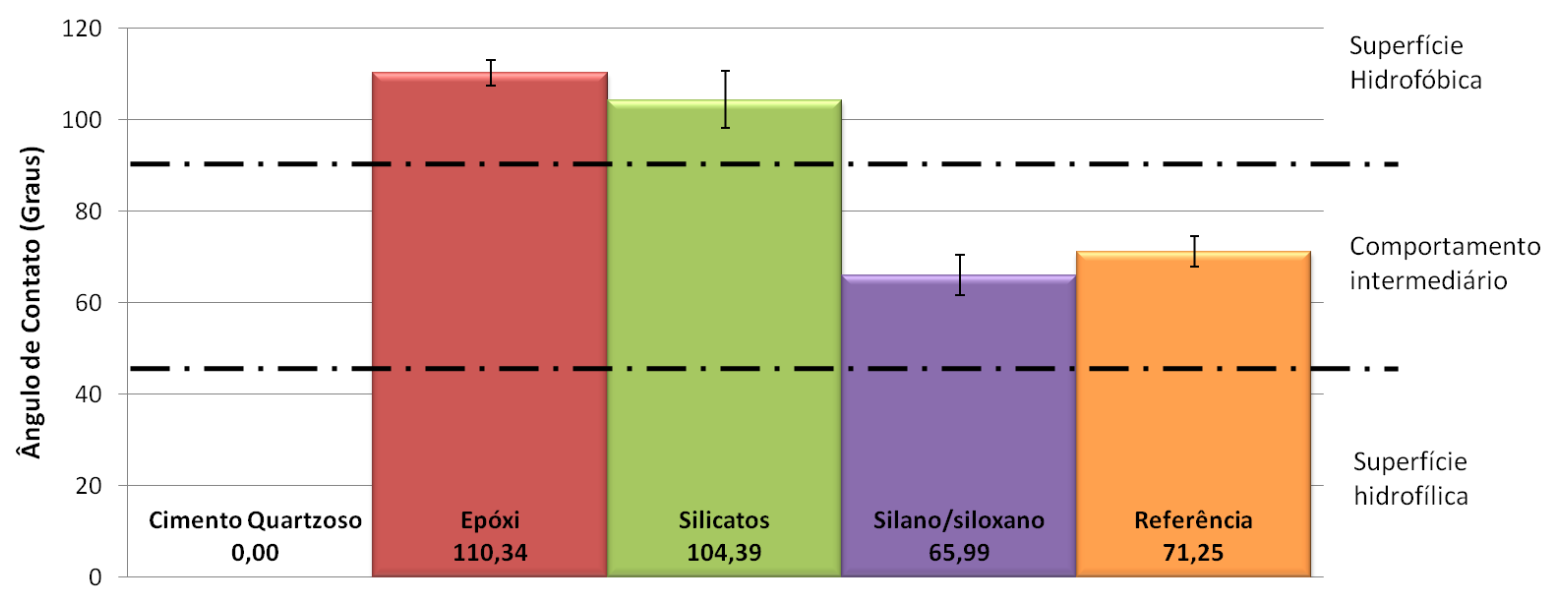

Figura 14: Ângulo de contato das amostras ensaiadas.

Os produtos Epóxi e a base de silicatos, que apresentaram os menores valores de sortividade, foram os que apresentaram os maiores valores de ângulo de contato, sendo classificados como os de menor afinidade com a água entre as superfícies testadas, indicando uma maior eficiência destes sistemas de tratamento. O produto silano/siloxano apresentou média do ângulo de contato inferior a série de referência, porém seu desvio padrão permite dizer que as médias deste produto e da série de referência não são estatisticamente diferentes, indicando que o silano/siloxano não muda o grau de afinidade com a água da superfície tratada. 
A Figura 15 mostra o gráfico de relação dos dados de ângulo de contato com a água e os ensaios de absorção e de migração de cloretos. Aparentemente não existe uma relação direta entre os resultados de ângulo de contato e os dois ensaios.

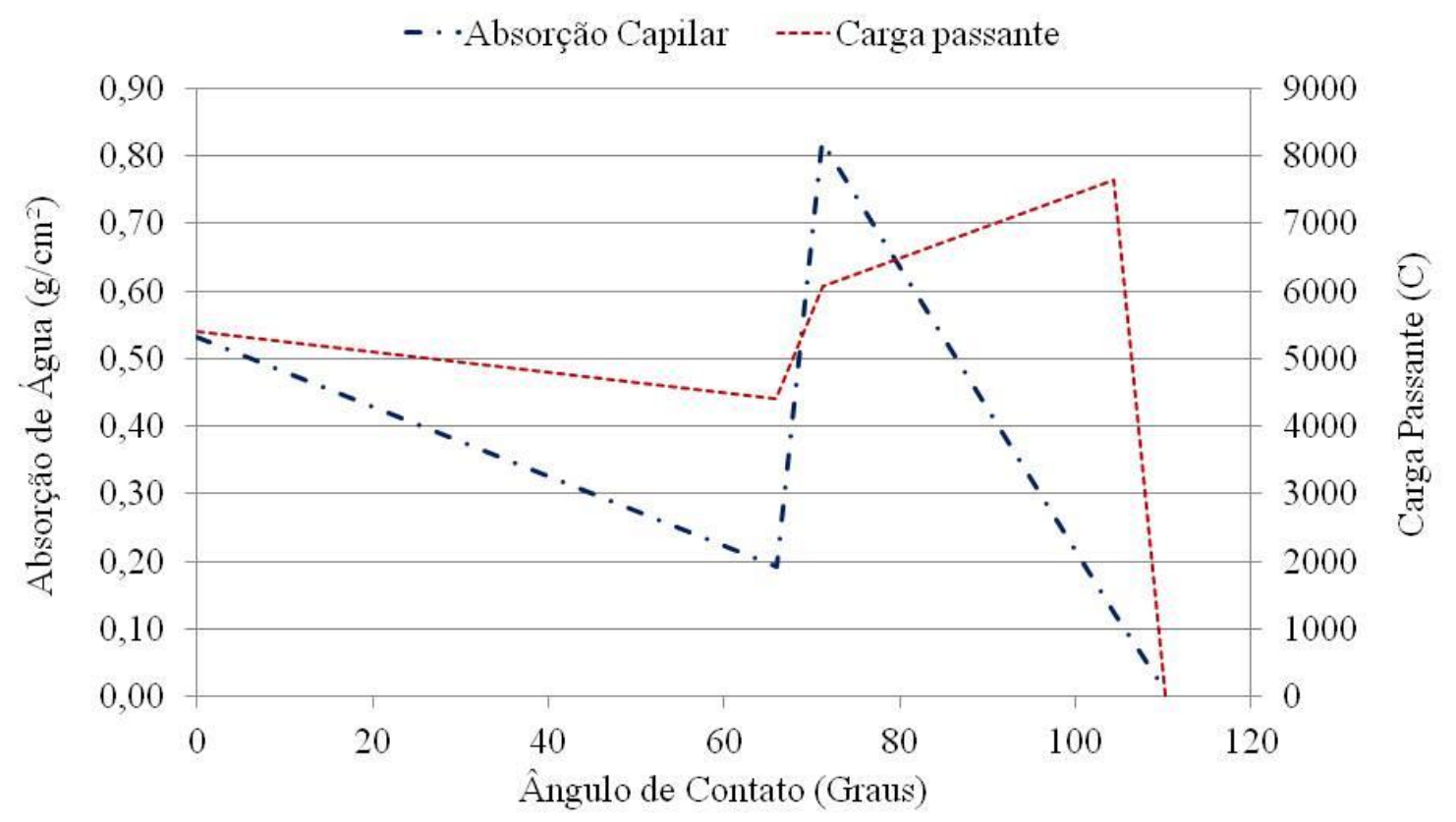

Figura 15: Correlação entre os três ensaios realizados.

Os resultados encontrados neste trabalho estão de acordo com os obtidos por Dang et al. [22], que comparando produtos de proteção de superfície como silano, epóxi e metacrilato, também chegaram a resultados que evidenciam o epóxi como o de maior capacidade de elevação do ângulo de contato e de reduzir a absorção de água. Neste trabalho também ficou evidenciado que o silano proporcionou pouca modificação do ângulo de contato com a água, quando comparado com a base cimentícia sem tratamento de superfície (série de referência). Vale salientar de forma complementar que Aguiar e Cristela Júnior [23] comparando a eficiência de um epóxi, um acrílico e um siloxano como sistemas de proteção de superfície para peças de concreto com foco na redução da velocidade de carbonatação, concluíram que o epóxi foi o material com maior potencial de redução da cinética da carbonatação do concreto, embora os outros dois materiais de proteção também apresentaram capacidade de redução da evolução da frente de carbonatação.

Apesar de os resultados apresentados serem favoráveis ao uso do epóxi, deve-se ressaltar que os demais produtos não podem ser ignorados e estudos adicionais devem ser conduzidos. Além disto, cabe destacar que o conhecimento da durabilidade destes produtos é essencial. O comportamento dos tratamentos de superfície expostos às intempéries e principalmente a radiação UV deve ser avaliada, uma vez que este tende a ser um agente de degradação. O conhecimento sobre a estabilidade dos produtos de tratamento de superfície fornecerá subsídios ao meio técnico sobre o momento conveniente de intervenções sobre o concreto e sobre o tempo necessário para a manutenção, garantindo-se assim a eficiência da camada de proteção. Outro fator relevante é o custo benefício do uso destes produtos. Verifica-se a necessidade em trabalhos futuros de verificar-se o custo da aplicação destes produtos para o uso como tratamento superficial a fim de que estes dados possam ser utilizados como critério de tomada de decisão sobre qual sistema utilizar-se.

\section{CONCLUSÕES}

Na maioria dos casos, pode-se afirmar que os tratamentos de superfície testados apresentaram a capacidade de modificar a interação entre a água e a superfície de contato com o corpo de prova de concreto. Nos casos em que esta modificação foi no sentido de aumentar o ângulo de contato com a água, isso significa que a ação do produto de proteção tem o poder de tornar o concreto hidrófugo, ou seja, com capacidade de repelir a água.

Exceto para o caso do tratamento de silicatos, no estudo de eficiência de sistemas de proteção de su- 
perfície para concreto existe uma forte correlação entre os resultados de absorção de água por capilaridade e o ensaio de migração de íons cloretos.

Comparando os produtos utilizados, deve-se destacar que o epóxi apresentou a maior resistência à penetração de cloretos, a menor absorção de água por capilaridade e o maior ângulo de contato médio com a água, sendo configurado como o produto com maior potencial de proteger uma estrutura de concreto armado em ambiente contaminado por íons cloretos. Por outro lado, o produto de cimento quartzoso apresenta os piores resultados quanto à absorção e resistência a penetração de íons. Além disto, nos ensaios de avaliação do ângulo de contato a água é absorvida imediatamente pela superfície do concreto, não sendo possível nem mesmo avaliar o ângulo de contato.

É importante enfatizar que a decisão sobre qual o produto de proteção de superfície a ser especificado, em um caso de estrutura de concreto armado em contato com ambiente contaminado com cloretos, deve também levar em consideração a resistência à radiação UV de cada um dos produtos possíveis. Isso é importante porque um produto que tem baixa resistência à radiação ultravioleta irá apresentar pouca durabilidade da capacidade de proteção e resultará em falha em curto espaço de tempo, se estiver em contato com os raios solares.

\section{AGRADECIMENTOS}

A equipe agradece ao apoio da Universidade Federal do Paraná (UFPR) e a Universidade Estadual de Ponta Grossa (UEPG) por possibilitar o empenho de seus professores/pesquisadores e colocar a sua infraestrutura a disposição deste trabalho de pesquisa.

\section{BIBLIOGRAFIA}

[1] MEDEIROS, M.H.F., HELENE, P., "Efficacy of Surface Hydrophobic Agents in Reducing Water and Chloride Ion Penetration in Concrete", Materials and Structures, v. 41, n. 1, pp. 59-71, 2008.

[2] MEDEIROS, M.H.F., HELENE P., "Surface treatment of reinforced concrete in marine environment: Influence on chloride diffusion coefficient and capillary water absorption", Construction and Building Materials, v. 23, n. 3, pp. 1476-1484, 2009a.

[3] HO, D.W.S., MARK, S.L., "Interactions between surface coatings and their concrete substrate", In: $R e$ pair, Rehabilitation, and Maintenance of Concrete Structures, and Innovations in Design and Construction, Coréia, ACI International, pp. 370-380, 2000.

[4] BROOMFIELD, J.P., Corrosion of steel in concrete - Understanding, investigation and repair, 1ed., Londres, E \& FN SPON, 1997.

[5] MEDEIROS, M.H.F., Contribuição ao estudo da durabilidade de concretos com proteção superficial frente à ação de íons cloretos, Tese de D.Sc., Escola Politécnica/Universidade de São Paulo, São Paulo, SP, Brasil, 2008.

[6] MEDEIROS, M. H. F., HELENE, P., "Durabilidade e Proteção do Concreto Armado", Téchne: Revista de Tecnologia da Construção (São Paulo), v. 151, pp. 50-54, $2009 \mathrm{~b}$.

[7] DIAMANTI, M.V., BRENNA, A., BOLZONI, F., et al., "Effect of polymer modified cementitious coatings on water and chloride permeability in concrete", Construction \& Building Materials, v. 49, pp. 720-728, 2013.

[8] BRENNA, A., BOLZONI, F., BERETTA, S., et al., "Long-term chloride-induced corrosion monitoring of reinforced concrete coated with commercial polymer-modified mortar and polymeric coatings", Construction \& Building Materials, v. 48, pp. 734-744, 2013.

[9] ZEMAJTIS, J., WEYERS, R. E., "Concrete bridge service life extension using sealers and coatings in chloride-laden environments", In: Concrete in the Service of Mankind - Concrete Repair, Rehabilitation and Protection, Escócia, E \& FN SPON, pp. 389-398, 1996.

[10] HELENE, P., "Protección y Mantenimiento de las Superfícies de Hormigón”, In: CASANOVAS, X. (ed), Manual de Diagnosis e Intervención en Estructuras de Hormigón Armado, 1. ed., Capítulo 12, Espanha, Col-legi d'Aparelladors i Arquitectes Tècnics de Barcelona, 2000.

[11] BENTUR, A., DIAMOND, S., BERKE, N. S. Steel Corrosion in Concrete - Fundamentals and Civil Engineering Practice, 1. ed., London, E and FN SPON, 1997. 
[12] CHRISTODOULOU, C., GOODIER, C.I., AUSTIN, S.A., et al., "Long-term performance of surface impregnation of reinforced concrete structures with silane", Construction \& Building Materials, v. 48, pp. 708-716, 2013.

[13] ASSOCIAÇÃO BRASILEIRA DE NORMAS TÉCNICAS (ABNT). Argamassa e concreto endurecidos - Determinação da absorção de água por capilaridade. NBR 9779. Rio de Janeiro. 2012.

[14] AMERICAN SOCIETY FOR TESTING AND MATERIALS (ASTM). Standard test method for electrical indication of concrete's ability to resist chloride ion penetration. ASTM C-1202. In: Annual book of ASTM Standards. West Conshohocken, 2012.

[15] AMERICAN SOCIETY FOR TESTING AND MATERIALS (ASTM). Standard Practice for Surface Wettability of Coatings, Substrates and Pigments by Advancing Contact Angle Measurement. ASTM D-7334. In: Annual book of ASTM Standards. West Conshohocken, 2008.

[16] ASSOCIAÇÃO BRASILEIRA DE NORMAS TÉCNICAS (ABNT). Concreto - Ensaios de compressão de corpos-de-prova cilíndricos. NBR 5739. Rio de Janeiro, 2007.

[17] MEDEIROS, M.H.F., HOPPE FILHO, J., HELENE P., "Influence of the slice position on chloride migration tests for concrete in marine conditions", Marine Structures, v. 22, n. 2, pp. 128-141, 2009.

[18] MARANHÃO, F., LOH, K. U., “O uso de hidrofugantes em materiais de construção porosos”, Techne: Revista de Tecnologia da Construção, v. 155, pp. 4-7, 2010.

[19] KROPP, J., HILSDORF, H.K., GRUBE, H., et al., "Transport mechanisms and definitions”, In: KROPP, J.; HILSDORF, H. K. (eds), Performance Criteria for Concrete Durability, Capítulo 2, Londres, Inglaterra, E \& FN Spon, 1995.

[20] NEPOMUCENO, A.A. "Mecanismo de transporte de fluidos no concreto", In: Isaia, G. (ed), Concreto: Ensino, Pesquisa e Realizações, 1. ed., Capítulo 26, Volume 2, São Paulo, Brasil, IBRACON, 2005.

[21] RAISDORFER, J. W., PAIM, A. S., SANTOS, I. M. R., et al., Caracterização de concretos tratados com produtos cristalizantes para impermeabilização de piscinas com tratamento de água a base de cloreto de sódio, Revista de Engenharia e Tecnologia. v. 5, n. 2, pp. 111-123. 2013.

[22] DANG, Y., XIE, N., KESSEL, A., et al., "Accelerated laboratory evaluation of surface treatments for protecting concrete bridge decks from scaling", Construction \& Building Materials, v. 55, pp. 128-135, 2014. [23] AGUIAR, J.B., CRISTELA JÚNIOR., "Carbonation of surface protected concrete", Construction \& Building Materials, v. 49, pp. 478-483, 2013. 